\title{
Movement behaviour of skipjack (Katsuwonus pelamis) and yellowfin (Thunnus albacares) tuna at anchored fish aggregating devices (FADs) in the Maldives, investigated by acoustic telemetry
}

\author{
Rodney Govinden ${ }^{1}$, Riyaz JAUHARY ${ }^{2}$, John FILMALTER ${ }^{3,4}$, Fabien ForGeT ${ }^{3,4}$, Marc Soria ${ }^{5}$, \\ Shiham ADAM ${ }^{2}$ and Laurent DAGORN ${ }^{3, a, b}$ \\ ${ }^{1}$ Seychelles Fishing Authority (SFA), PO Box 449, Victoria, Mahé, Seychelles \\ 2 Marine Research Centre, Ministry of Fisheries and Agriculture, Maldives \\ 3 Institut de Recherche pour le Développement (IRD), UMR 212, PO Box 570, Victoria, Mahé, Seychelles \\ 4 South African Institute for Aquatic Biodiversity (SAIAB), Private Bag 1015, 6140 Grahamstown, South Africa \\ 5 Institut de Recherche pour le Développement (IRD), UMR 212, Parc Technologique Universitaire, PO Box 172, \\ 97492 Sainte Clotilde Cedex, La Réunion, France
}

Received 12 March 2012; Accepted 14 June 2012

\begin{abstract}
The pole and line tuna fishery in the Maldives relies heavily on an array of 45 anchored fish aggregating devices (FADs), making it one of the largest anchored FAD-based tuna fisheries in the world. We examined the behaviour of skipjack (Katsuwonus pelamis) and yellowfin (Thunnus albacares) tuna around anchored FADs (1 000 to $2000 \mathrm{~m}$ deep) in the Maldives using passive acoustic telemetry. Eight neighbouring FADs (distance range: 30 to 95 $\mathrm{km}$, average: $50 \mathrm{~km}$ ) were equipped with automated acoustic receivers in January 2009, for a period of 13 months. A total of 40 skipjack (37-54 $\mathrm{cm} F L)$ and 21 yellowfin $(35-53 \mathrm{~cm} F L)$ tuna were tagged with Vemco V13 transmitters in January (start of the northeast monsoon, dry season) and November (end of the southwest monsoon, wet season) 2009 and released at the two central FADs within this instrumented array. No movement between FADs was observed for any acoustically-tagged tuna in the instrumented FAD array. These results suggest that FADs in the Maldives may act independently. The maximum time a tagged skipjack remained associated with a FAD was 12.8 days in January but only one day in November. In addition, residence times at FADs were found to differ with time (month) and space (FAD location) for skipjack tuna, suggesting that external biotic factors (e.g., prey, conspecifics or predators) might influence the time this species spends at FADs. In November, the residence times of yellowfin tuna (maximum observed time: 2.8 days) were three times greater than those of skipjack tuna at the same FADs. This specific difference could be explained either by the two species responding to different factors or by the species' responses being dependent on the same factor but with different thresholds. No particular preference for time of departure from the FADs was observed. Some monospecific and multispecific pairs of acoustically-tagged individuals were observed leaving the FADs simultaneously. Thus, this study indicates a high degree of complexity in the behavioural processes driving FAD associations.
\end{abstract}

Keywords: Behaviour / Fish Aggregating Devices / Passive acoustic telemetry / Skipjack tuna / Yellowfin tuna / Indian Ocean

\section{Introduction}

The association of tropical tunas (skipjack Katsuwonus pelamis, yellowfin Thunnus albacares, bigeye T. obesus) and several other pelagic fishes with floating objects has been well documented. The movement behaviour of tuna species around

\footnotetext{
a Corresponding author: laurent. dagorn@ird.fr

b Present address: Centre de Recherche halieutique méditerranéen et tropical, BP 171, 34203 Sète Cedex, France
}

anchored FADs has been investigated using conventional tagging methods (Kleiber and Hampton 1994; Itano and Holland 2000), active acoustic tracking (Holland et al. 1990; Cayré 1991; Cayré and Marsac 1993; Marsac and Cayré 1998; Brill et al. 1999; Dagorn et al. 2000a; Schaefer and Fuller 2005) and, more recently, by passive acoustic tracking (Klimley and Holloway 1999; Ohta and Kakuma 2005; Dagorn et al. 2007a; Mitsunaga et al. 2012; Robert et al. 2012). These studies have provided useful insights into the behaviour of tunas at anchored FADs. However, we still do not understand why tunas 
associate with FADs and what factors determine their residence times at FADs (Fréon and Dagorn 2000; Castro et al. 2002). Skipjack tuna was the first tuna species to be tracked using acoustic telemetry (Yuen 1970; Dizon et al. 1978). Cayré and Chabanne (1986) and Cayré (1991) actively tracked this species around anchored FADs in the late 1980s. However, the only subsequent research done on skipjack tuna at a moored FAD was conducted by Schaefer and Fuller (2005) around a single offshore oceanographic buoy. The majority of behavioural studies have primarily focused on yellowfin tuna (and to a lesser extent on bigeye tuna) in the Pacific Ocean. This clearly indicated the need for further research on yellowfin tuna in other areas of the world to facilitate comparative research on yellowfin and other tuna species such as skipjack tuna, the main species captured around FADs worldwide (Bromhead et al. 2003; Miyake et al. 2010; Dagorn et al. 2012).

Many countries in the Indian Ocean, such as the Maldives, Mauritius, Comoros and La Réunion, use anchored FADs to catch pelagic fishes. The Maldives have one of the largest anchored FAD fisheries in the world and Maldivians have been catching tuna for over 700 years, mainly around "oivaali", the local name for drifting objects (Shiham 2004). Deep-water anchored FADs (approximately $20 \mathrm{~km}$ offshore of the atolls and in water 1000-2000 $\mathrm{m}$ deep) were first introduced in the early 1980s (Naeem and Latheefa 1994). By 1990, there were 10 FADs deployed around the Maldives, with the national tuna catch increasing from $30000 \mathrm{t}$ in 1980 to $70000 \mathrm{t}$ in 1990 . Tuna catches in the Maldives peaked in 2006 with a catch of $166000 \mathrm{t}$ (138000 $\mathrm{t}$ of skipjack tuna and $23000 \mathrm{t}$ of yellowfin tuna), the majority of which came from anchored FADs. However, in 2010 the tuna catches plummeted to $77000 \mathrm{t}(59000 \mathrm{t}$ of skipjack tuna and $13000 \mathrm{t}$ of yellowfin tuna) (Maldives Ministry of Fisheries and Agriculture 2010, www.fishagri.gov. $\mathrm{mv})$. Due to its success, the Maldives currently maintain an array of about 45 FADs, making it the largest anchored FAD array in the Indian Ocean (Shainee and Leira 2011).

To date, no investigation of the behaviour of skipjack tuna has been reported using passive acoustic telemetry in an array of anchored FADs. Furthermore, the detailed behaviour of tunas at FADs in the Maldives has never been investigated, even though Maldivian fishery relies heavily on FADs and knowledge on key behavioural parameters is necessary for sound science-based fishery management. Several investigators have adopted passive acoustic telemetry to study the behaviour of tunas at FADs (Klimley and Holloway 1999; Ohta and Kakuma 2005; Dagorn et al. 2007a; Mitsunaga et al. 2012; Robert et al. 2012). In the present study, both skipjack and yellowfin tuna around the Maldivian FADs were tagged with acoustic transmitters. The following specific questions were addressed:

- Do tunas move between anchored FADs?

- How long do tunas remain associated with the anchored FADs?

- Are the durations of association species-specific, do they vary in time and are they FAD-specific?

- Is there a preferred time of departure; do associated tunas leave the FADs at the same time?

\section{Materials and Methods}

\subsection{Instrumented FAD array}

The 45 anchored FADs are moored around 26 natural atolls that make up the 1200 islands of the Maldives. Automated acoustic receivers (VR2W, Vemco, Halifax, Canada) were deployed on eight neighbouring anchored FADs on the eastern side of the archipelago to monitor movement between FADs (Fig. 1). Distances between the eight FADs equipped in this way ranged from 30 to $95 \mathrm{~km}$, and the total extent of the instrumented array was $300 \mathrm{~km}$. The acoustic receivers were attached directly to the FAD mooring lines using the following method. Firstly, a stainless steel $U$-bolt and heavy-duty snapclip were secured to the line $10 \mathrm{~m}$ below the surface. The acoustic receiver was then clipped onto this system and secured firmly to the mooring line using heavy-duty plastic cable ties. Acoustic receivers were orientated with the hydrophone facing downwards. The receivers were in place from January 2009 to January 2010.

\subsection{Tagging}

Acoustic tagging was conducted around two FADs (referred to as FAD1 and FAD2)in the middle of the instrumented network, during two different periods. The distance between these two FADs is $40 \mathrm{~km}$ (Fig. 1). The first tagging period was conducted between January 29 and February 1, 2009 (start of the northeast monsoon, dry season), while the second was conducted between November 17 and November 19, 2009 (end of the southwest monsoon, wet season). For simplicity, "January" and "November" will be used to differentiate between these two periods throughout the remainder of the text. Tunas were caught using two different techniques: trolling around the FADs using artificial lures with barbless hooks to minimise injury to the fish (January), and traditional pole and line fishing using barbless hooks (November). Tuna identified for tagging were carefully transferred onto a " $\mathrm{V}$ " shaped tagging table, where a hose supplying sea water was inserted into the tunas' mouths to oxygenate the gills and the hook was carefully removed. The eyes of the fish were covered using a wet artificial chamois material. Only healthy fish with no apparent injury or significant bleeding were tagged. The fork length $(F L)$ of each fish was measured to the nearest $\mathrm{cm}$ using a measuring ruler.

The transmitters (Vemco V13-1L-R64K, 69 kHz, 50-130 s delay, estimated battery life 878 days) were surgically implanted into the tunas following standard fish tag implantation techniques (e.g., Meyer et al. 2000; Schaefer and Fuller 2002). A sharp scalpel was used to make a $1-1.5 \mathrm{~cm}$ incision in the abdominal musculature, approximately $2-3 \mathrm{~cm}$ proximal to the anus. A transmitter was then inserted into the peritoneal cavity and the incision closed with two independent monofilament nylon non-absorbable sutures. To facilitate identification of the fish in the case of recaptures, all fish were also tagged with external plastic dart tags (PDT) inserted through the pterygiophores of the second dorsal fin. All fish were released within $300 \mathrm{~m}$ of the anchored FAD of capture. Large variations in detection range are known to occur 


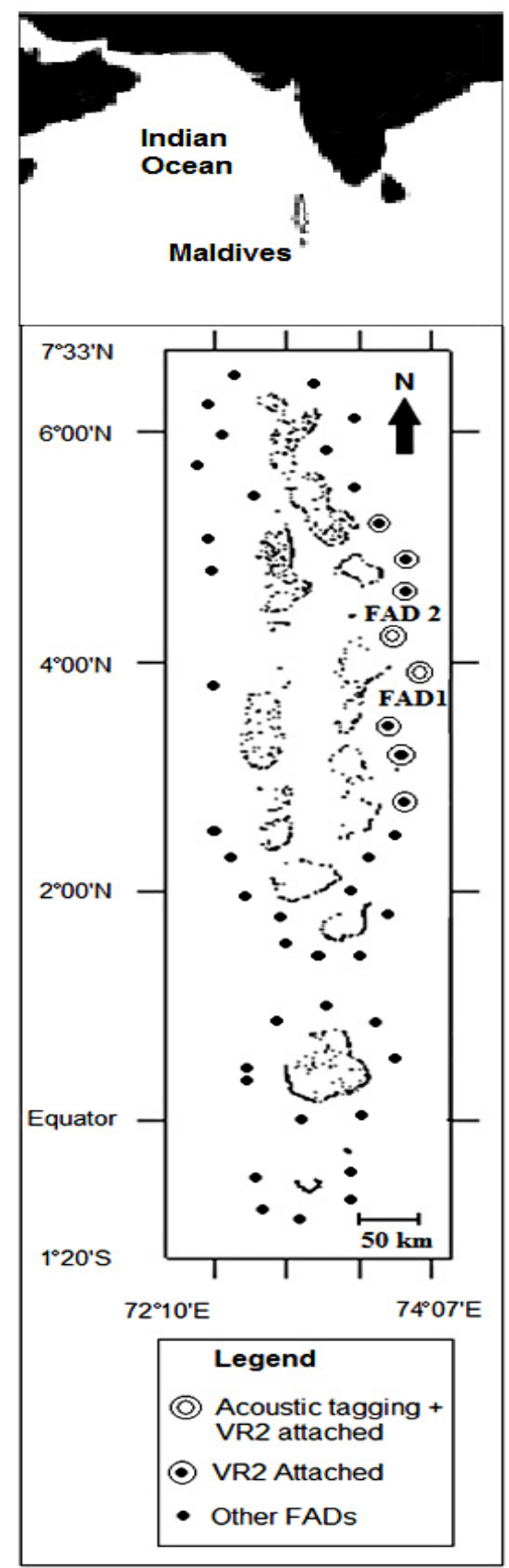

Fig. 1. Map of the Maldives showing locations of anchored fish aggregating devices (FADs). Black dots indicate FADs. Open circles indicate the FADs where fish were tagged: FAD1 and FAD2. Black dots surrounded by open circles indicate FADs equipped with listening stations.

and these are typically attributed to fluctuations in local conditions, such as wind, sea temperature, depth of the thermocline, salinity, turbidity, presence of vessels, etc. (Pincock and Voegeli 1990). As such, obtaining an understanding of the detection range requires lengthy experiments to incorporate such environmental variations. The practical difficulties and cost of conducting such experiments at offshore anchored FADs precluded us from completing a thorough range test. Instead,
Table 1. Acoustic tagging summary: anchored FAD of release, tagging periods and number of tunas tagged.

\begin{tabular}{lcc}
\hline $\begin{array}{l}\text { FAD of } \\
\text { release }\end{array}$ & $\begin{array}{c}\text { Periods of } \\
\text { tagging }\end{array}$ & $\begin{array}{c}\text { Number of } \\
\text { skipjack-yellowfin } \\
\text { tunas tagged }\end{array}$ \\
\hline 1 & 29 Jan. -1 Feb. 2009 & $13-0$ \\
2 & 29 Jan. -1 Feb. 2009 & $10-0$ \\
1 & 17-19 Nov. 2009 & $5-10$ \\
2 & 17-19 Nov. 2009 & $12-11$ \\
\hline
\end{tabular}

we provide the theoretical ranges estimated using the range calculator provided by Vemco (www.vemco.com) for V13-1L tags (147 dB re $1 \mu \mathrm{Pa} @ 1 \mathrm{~m}$ ): $282 \mathrm{~m}$ (for 30-34 knots) and $539 \mathrm{~m}$ (depth).

A total of 40 skipjack tuna and 21 yellowfin tuna equipped with internal acoustic transmitters were released at the two anchored FADs, FAD1 and FAD2 (Fig. 1, Table 1). During January 2009, only skipjack tuna were tagged; during November 2009 , however, both skipjack and yellowfin tuna were tagged.

\subsection{Data analysis}

The residence time of tagged tunas at a FAD was investigated at two temporal scales. First, the continuous residence time (CRT), defined by Ohta and Kakuma (2005) as "the duration in which a tagged tuna was continuously monitored without day-scale (>24 h) absences" was calculated. However, CRTs mask the short excursions that tunas are known to make when associated with FADs (Holland et al. 1990). Hence, the fine-scale residence time (FCRT), defined as the duration over which a tagged tuna was monitored without a one-hour absence, was also calculated to investigate the finescale behaviour of tagged tunas.

Following the same analytical procedures used by Robert et al. (2012), survival curves of CRTs and FCRTs were compared using the Cox proportional hazards regression model (Cox 1972) to examine whether differences existed between species, between the two study periods, between the two FADs and between two size classes for both skipjack and yellowfin tuna. The size classes for skipjack tuna were $<40 \mathrm{~cm}$ and $\geqslant 40 \mathrm{~cm} F L$, whilst for yellowfin tuna, they were $<50 \mathrm{~cm}$ and $\geqslant 50 \mathrm{~cm} \mathrm{FL}$. Due to lack of data, this comparison was only possible in January for skipjack tuna and in November for yellowfin tuna using the FCRT data. The $40 \mathrm{~cm} F L$ threshold chosen for skipjack tuna corresponds to the size at first maturity for this species (Stéquert and Ramcharrun 1996). The size threshold chosen for yellowfin tuna was $50 \mathrm{~cm} F L$, as Graham et al. (2007) and Robert et al. (2012) reported differences in the ecology and behavioural patterns of FAD-associated yellowfin tuna at this size. The Wald statistics of the Cox regression model were used to test the null hypothesis that the survival curves were identical.

We calculated the hourly frequency of departures from FADs using the FCRT data to assess whether the tuna left the FADs at regular times. Diurnal differences in the departure events were investigated by comparing the number of departures occurring during daytime (06:00-17:59) and night-time (18:00-05:59), using a Mann-Whitney $U$ test. 
To investigate whether some tunas left the FADs at the same time, we calculated the difference in time between successive departures of tagged tunas from the same FAD. However, to define the time window that could be considered as a simultaneous multiple departure event, we must consider both the time intervals between two acoustic transmissions of a given transmitter, and the possible collisions between acoustic signals coming from different transmitters emitting at the same time (Heupel et al. 2006). The transmitters are set to transmit a signal every $50-130 \mathrm{~s}$. Using the Vemco collision estimator tool (www.vemco.com), 19 min are required to detect all tags when 15 tags (maximum numbers of tagged tunas present at any point during the experiment) are present. Therefore, a synchronous departure was defined as two or more tuna leaving a FAD within 15 min of each other. This analysis was conducted using the fine-scale residence time dataset (FCRTs).

All statistical tests were carried out using the statistical package $R$ (2.13.0). A significance level of $\alpha=0.05$ was used throughout the analyses.

\section{Results}

\subsection{Acoustic tagging}

Of the 28 fish released at FAD1 (January and November combined), one skipjack tuna was never detected and three skipjack tuna were detected only once (single detections). Moreover, of the 33 tuna released at FAD2 (January and November combined) two skipjack and one yellowfin tuna were never detected, whilst two skipjack tuna were detected only once. The size of skipjack tuna tagged in January ranged from 37.0 to $46.0 \mathrm{~cm} F L$ (mean $39.9 \mathrm{~cm}$; SD $2.7 \mathrm{~cm}$ ). Skipjack tuna tagged in November ranged from 37.0 to $54.0 \mathrm{~cm} F L$ (mean $46.3 \mathrm{~cm}$; SD 4.5). Yellowfin tuna tagged in November ranged from 35.0 to $53.0 \mathrm{~cm} F L$ (mean $47.5 \mathrm{~cm}$; SD $0.9 \mathrm{~cm}$ ) (Fig. 2).

Movements between FADs: no acoustically-tagged tunas were detected by receivers at FADs other than the ones from which they had been released.

\subsection{Residence times at FADs}

\subsubsection{Continuous residence time (CRT, no day-scale absence)}

All the acoustically-tagged tuna remained associated with the anchored FAD from which they were released, without undertaking any excursions greater than $24 \mathrm{~h}$ until they left the FAD permanently. The CRTs therefore also correspond to the total time of association and, as no movement was observed between FADs, the CRTs are also equivalent to the residence time of acoustically-tagged tuna in the instrumented FAD array. Skipjack tuna remained associated with FADs for significantly longer periods in January than in November (Wald test, $p<0.01$ ) (Figs. 3a,b, Table 2). Within the month of January, no difference was found between the durations of association at the two FADs where skipjack tuna were tagged (Wald test, $p=0.75$ ) (Figs. 3a,b, Table 2). During November, skipjack
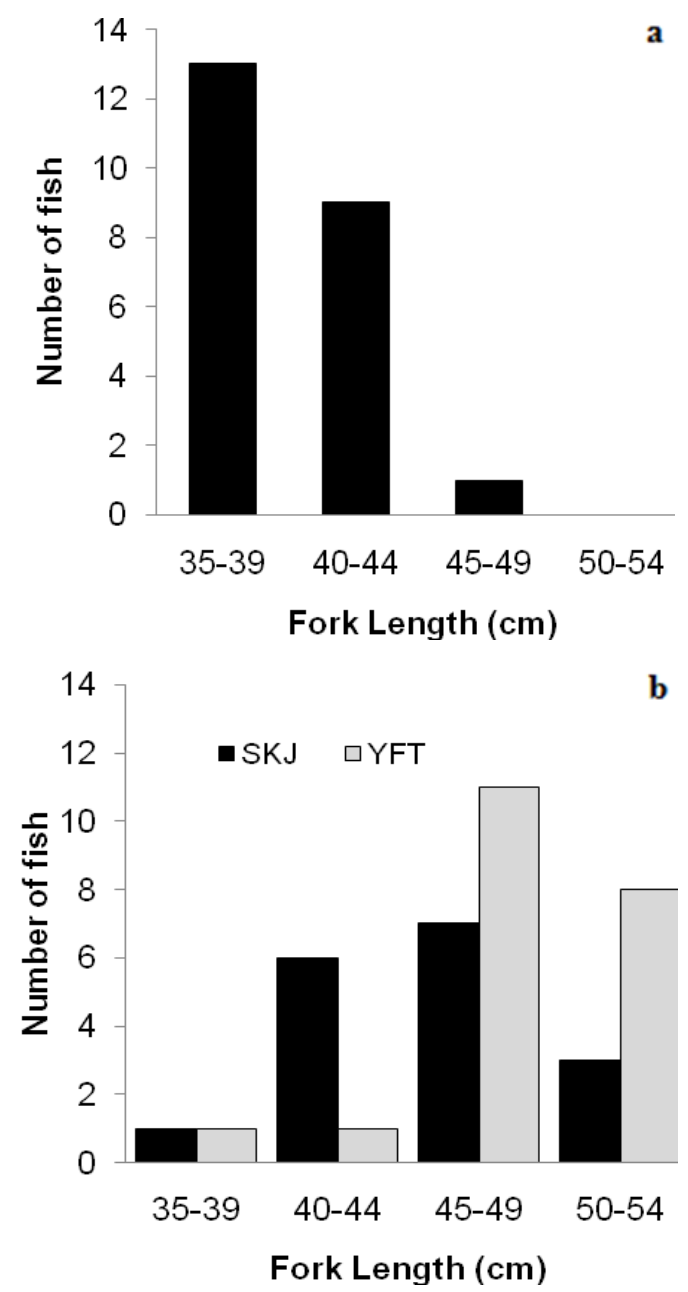

Fig. 2. Length frequency distribution for: (a) skipjack tuna (SKJ) acoustically-tagged in January and (b) skipjack and yellowfin (YFT) tuna acoustically-tagged in November.

tuna stayed around the FADs for approximately a third the length of the time that yellowfin tuna did (Wald test, $p<0.01$ ) (Figs. 3c,d, Table 2). Within the same month, no difference was observed between the association times of yellowfin tuna at the two FADs (Wald test, $p=0.926$ ).

\subsubsection{Fine-scale continuous residence time (FCRT, no hour-scale absence)}

In January, 33 FCRTs were measured from 17 skipjack tuna, of which only seven showed a total of 16 excursions of more than one hour (Figs. 3a,b). In November, 17 FCRTs were measured from 15 skipjack tuna, with only two of them showing two excursions of more than one hour (Figs. 3c,d). Within the same month, 26 FCRTs were measured from 20 yellowfin tuna, of which only three displayed a total of six excursions of more than one hour (Figs. 3c,d).

All comparisons of FCRTs followed the same trend as that observed with CRTs (Table 2). Skipjack tuna remained associated for longer (almost 12 times longer) in January than in November (Wald test, $1.83 \times 10^{-5}$ ), residence times of 

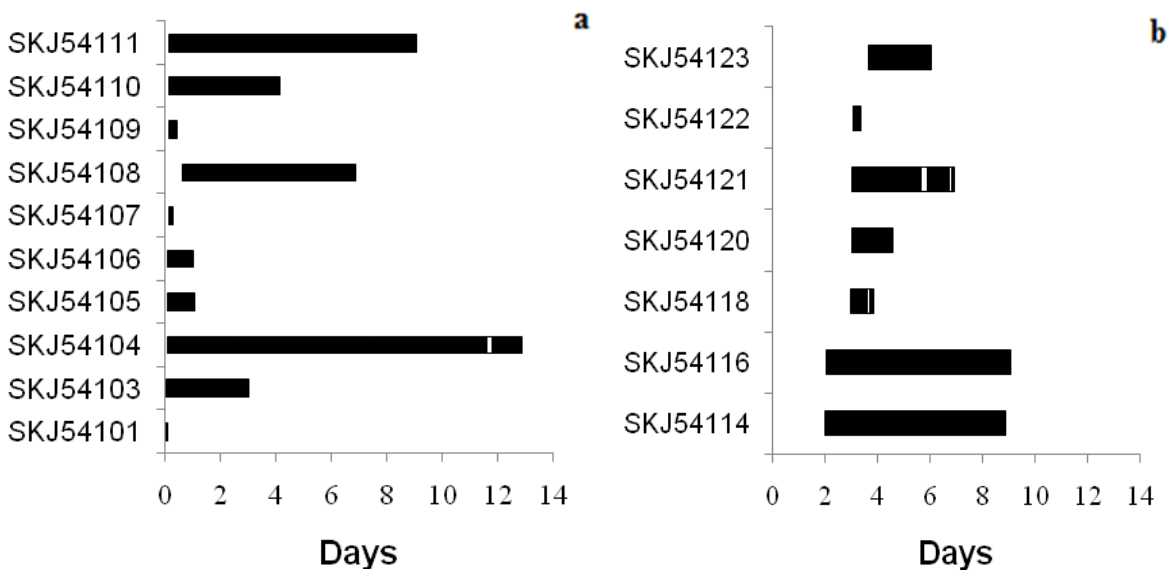

b
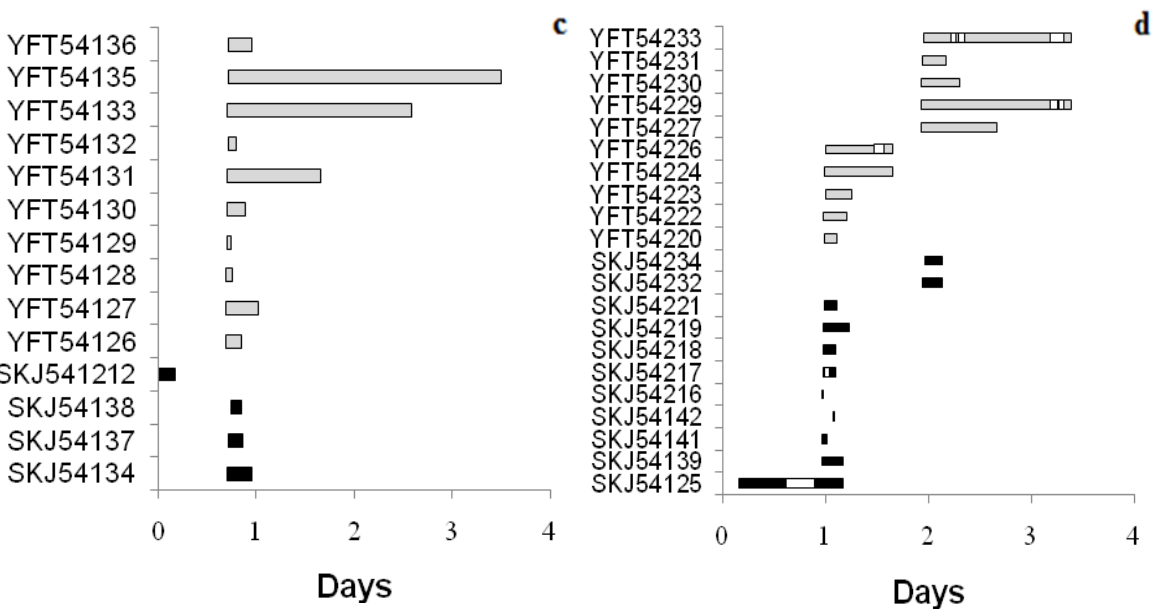

Fig. 3. Residency times for: (a) 10 skipjack tuna at FAD1 in January, (b) 7 skipjack at FAD2 in January, (c) 10 yellowfin tuna and 4 skipjack at FAD1 in November and (d) 10 yellowfin and 11 skipjack at FAD2 in November. Black (skipjack tuna) and grey (yellowfin tuna) bars correspond to the fine-scale continuous residence times (FCRTs) and white bars represent absences of an hour or more.

yellowfin tuna were longer (by approximately three times) than those of skipjack tuna in November (Wald test, $p=0.015$ ) and no difference between the FCRTs of yellowfin tuna at FAD1 and FAD2 was observed (Wald test, $p=0.365$ ). The only difference observed was for skipjack tuna, which remained associated for longer (approximately double the time) at FAD1 than at FAD2 when the FCRTs were examined (Wald test, $p=0.025$ ). No such difference was observed for CRTs.

We also compared the FCRTs between the two size classes for both skipjack and yellowfin tuna. No effect of fish size was observed for either species over the entire study (skipjack tuna $<40 \mathrm{~cm} F L$ and $\geqslant 40 \mathrm{~cm}$ in January; yellowfin tuna $<50 \mathrm{~cm} F L$ and $\geqslant 50 \mathrm{~cm}$ in November) (Table 2).

\subsection{Departure time and synchronous departure}

In January, skipjack tuna left the FADs throughout the day and night (no difference between day and night, MannWhitney $U$ test, $p>0.05$ ), but a minor peak in departures was observed between 09:00 and 11:00 h (Fig. 4a). In contrast, in November, $82 \%$ of departure events of skipjack tuna occurred between 12:00 and 18:00 h (Fig. 4b), resulting in a significant difference in the numbers of departures between day and night (Mann-Whitney $U$ test, $p=0.02$ ). Yellowfin tuna did not show any temporal pattern in departure events, with no difference between day and night (Mann-Whitney $U$ test, $p>0.05$ ) (Fig. 4b).

The majority of departure events $(84 \%)$ corresponded to an acoustically-tagged tuna leaving the FAD alone, i.e., without any other tagged tuna (Fig. 5). At most, two tagged tunas were observed to leave together: $5 \%$ of departures were pairs of skipjack tuna, $7 \%$ were pairs of yellowfin tuna and $4 \%$ comprised a skipjack and a yellowfin leaving together. The majority of synchronous departures $(75 \%)$ occurred at FAD2 in November.

\section{Discussion}

Acoustically-tagged yellowfin tuna have been observed to move between anchored FADs (Holland et al. 2000; Ohta and Kakuma 2005; Dagorn et al. 2007a; Mitsunaga et al. 2012; Robert et al. 2012); however, within the array of FADs in the Maldives, no such movements were observed for either yellowfin or skipjack tuna. In a previous large scale conventional tagging study in the Maldives, only 7 of the 104 recaptured 
Table 2. Results of the Cox Regression models used to compare different distribution of continuous residence time (CRT) and fine-scale residence time (FCRT) of skipjack and yellowfin at the two FADs. Descriptive statistics of CRT and FCRT for each of the indices are given for comparison.

\begin{tabular}{|c|c|c|c|c|c|c|c|c|c|}
\hline & \multicolumn{3}{|c|}{ Global test } & \multicolumn{2}{|c|}{$\begin{array}{c}\text { Estimated parameters of } \\
\text { the Cox model }\end{array}$} & \multicolumn{4}{|c|}{ Descriptive statistics of indices } \\
\hline & $N$ & Test name & $p$-value & $\operatorname{Exp}(\operatorname{coef})$ & $\mathrm{Se}($ coef $)$ & Min & Mean & Max & SD \\
\hline & \multicolumn{9}{|c|}{ Continuous residence time (CRT) } \\
\hline SKJ Jan. & 17 & Wald & $4.43 \times 10^{-5}$ & 7.62 & 0.50 & 0.09 & 3.55 & 12.80 & 3.69 \\
\hline SKJ Nov. & 15 & & & & & $<0.01$ & 0.20 & 1.02 & 0.24 \\
\hline SKJ Nov. & 15 & Wald & 0.006 & 0.35 & 0.38 & $<0.01$ & 0.20 & 1.02 & 0.24 \\
\hline YFT Nov. & 20 & & & & & 0.05 & 0.66 & 2.79 & 0.72 \\
\hline SKJ Jan. FAD1 & 10 & Wald & 0.75 & 1.18 & 0.52 & 0.09 & 3.75 & 12.80 & 4.34 \\
\hline SKJ Jan. FAD2 & 7 & & & & & 0.25 & 3.27 & 7.05 & 2.79 \\
\hline YFT Nov. FAD1 & 10 & Wald & 0.926 & 1.04 & 0.48 & 0.05 & 0.70 & 2.79 & 0.93 \\
\hline \multirow[t]{2}{*}{ YFT Nov. FAD2 } & 10 & & & & & 0.13 & 0.61 & 1.46 & 0.49 \\
\hline & \multicolumn{9}{|c|}{ Fine-scale continuous residence time (FCRT) } \\
\hline SKJ Jan. & 33 & Wald & $1.83 \times 10^{-5}$ & 5.90 & 0.41 & $<0.01$ & 1.79 & 8.96 & 2.02 \\
\hline SKJ Nov. & 17 & & & & & $<0.01$ & 0.15 & 0.46 & 0.12 \\
\hline SKJ Nov. & 17 & Wald & 0.015 & 0.43 & 0.35 & $<0.01$ & 0.15 & 0.46 & 0.12 \\
\hline YFT Nov. & 26 & & & & & $<0.01$ & 0.48 & 2.79 & 0.64 \\
\hline SKJ Jan. FAD1 & 14 & Wald & 0.025 & 2.34 & 0.38 & 0.09 & 2.65 & 8.96 & 2.47 \\
\hline SKJ Jan. FAD2 & 19 & & & & & $<0.01$ & 1.15 & 4.69 & 1.36 \\
\hline YFT Nov. FAD1 & 10 & Wald & 0.365 & 1.49 & 0.44 & 0.05 & 0.67 & 2.79 & 0.94 \\
\hline YFT Nov. FAD2 & 16 & & & & & $<0.01$ & 0.35 & 1.25 & 0.35 \\
\hline SKJ Jan. $35-39 \mathrm{~cm}$ & 22 & Wald & 0.187 & 1.66 & 0.38 & $<0.01$ & 1.39 & 4.86 & 1.63 \\
\hline SKJ Jan. > $40 \mathrm{~cm}$ & 11 & & & & & 0.09 & 2.59 & 8.96 & 2.52 \\
\hline YFT Nov. $<50 \mathrm{~cm}$ & 16 & Wald & 0.196 & 0.57 & 0.44 & $<0.01$ & 0.60 & 2.79 & 0.78 \\
\hline YFT Nov. $\geqslant 50 \mathrm{~cm}$ & 10 & & & & & 0.03 & 0.28 & 0.82 & 0.26 \\
\hline
\end{tabular}
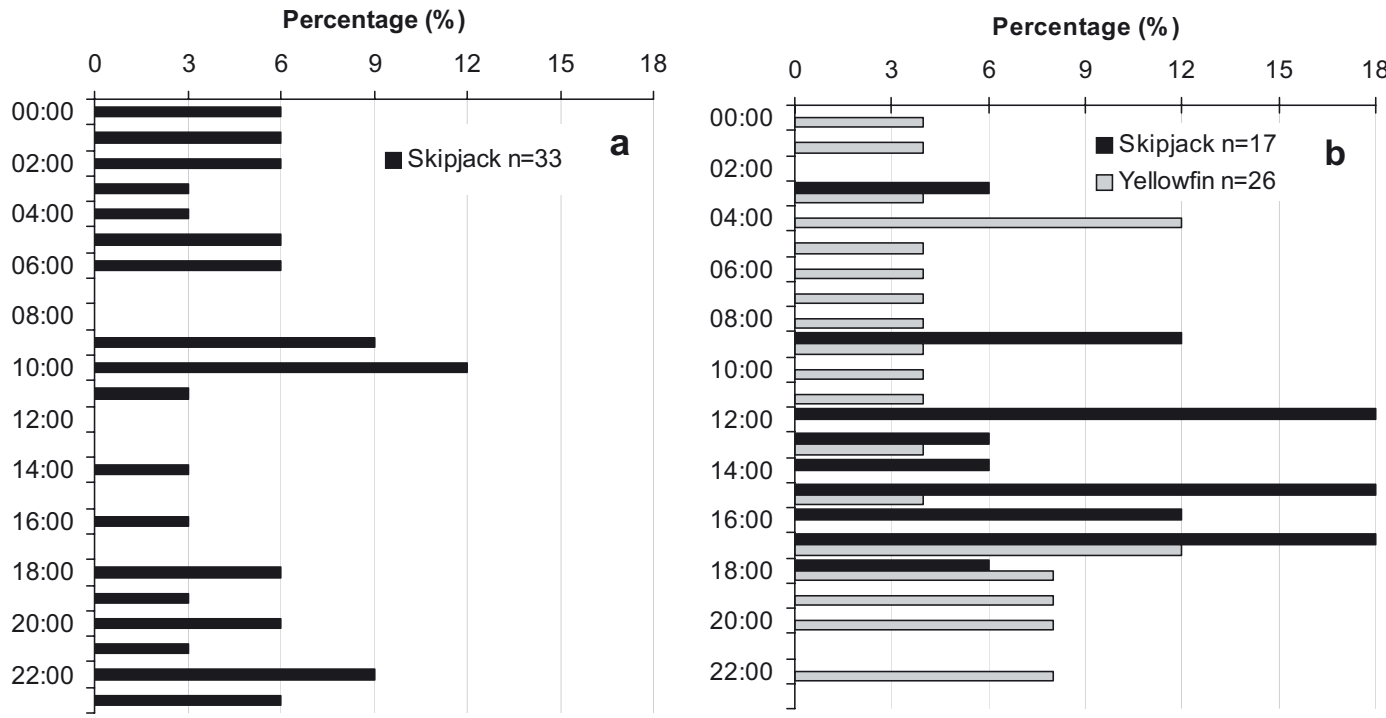

Fig. 4. Percentage number of departures in each hour of the day for: (a) skipjack tuna in January and (b) skipjack and yellowfin tuna in November, $n$ : number of departure events.

yellowfin tuna (7\%) and 51 of the 803 recaptured skipjack tuna $(6 \%)$ were caught at a different FAD than the one where they were tagged (Jauhary 2011). The absence of observed interFAD movement by our acoustically-tagged tunas and the few inter-FAD movements observed in the conventional tagging project tend to suggest that FADs in the Maldives are relatively independent. One possible explanation for the differences in inter-FAD movements observed between our results and those obtained from other FAD arrays could be the distance between FADs. In previous studies where inter-FAD movements were recorded, FADs were typically close to one another, e.g., 10-20 km apart in Hawaii (Dagorn et al. 2007a), while in the studied FAD array in the Maldives the average distance between FADs is $50 \mathrm{~km}$. However, this is quite surprising as tunas are known to travel long distances and their swimming speed (e.g., average swimming speeds of $47-55 \mathrm{~cm} \mathrm{FL}$ 


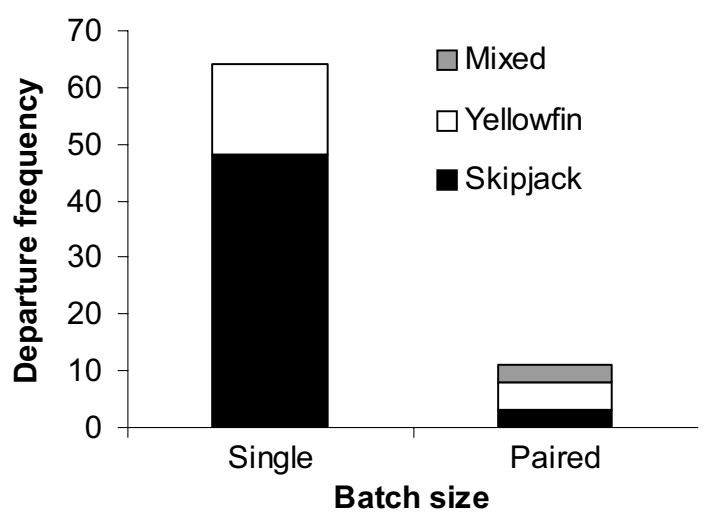

Fig. 5. Frequency of departures of skipjack tuna, yellowfin tuna and mixed batches (skipjack and yellowfin) for single departure (i.e., $84 \%)$ and paired departure (16\%) events.

yellowfin tuna range from 2.6 to $6.5 \mathrm{~km} \mathrm{~h}^{-1}$, Girard et al. 2004) would easily allow them to go from one FAD to the other in less than a day. Inter-FAD movements could instead be linked to the distance from which tuna could orientate to the FADs. Girard et al. (2004) determined that yellowfin tuna could orientate towards a FAD when they were within a radius of $10 \mathrm{~km}$ from it. Future studies should investigate the behaviour of tunas within arrays that have very different inter-FAD distances.

The CRTs observed for $35-53 \mathrm{~cm} \mathrm{FL}$ yellowfin tuna around FADs in the Maldives (mean 0.66 days) were shorter than those observed in any other study on anchored FADs, irrespective of size: 3-4 days for 19-31 cm FL yellowfin tuna in the Philippines (Mitsunaga et al. 2012), 4.0 days for yellowfin tuna $<50 \mathrm{~cm}$ and 1.6 days for yellowfin tuna $>50 \mathrm{~cm}$ in Hawaii (Robert et al. 2012), 8.0 days for yellowfin tuna 59-95 cm FL in Hawaii (Dagorn et al. 2007a), 12.8 days and 6.4 days for $45-85 \mathrm{~cm} F L$ and $86-120 \mathrm{~cm} F L$ yellowfin tuna in Japan, respectively (Ohta and Kakuma 2005). Robert et al. (2012) demonstrated that the residence times of yellowfin tuna at FADs can be affected by their size. The only study with yellowfin tuna of a comparable size (Robert et al. 2012) has demonstrated that the CRTs were approximately 6 times longer than those observed in the present study. The effects of fish size on residence times could only be tested using FCRTs due to the limited sample size in this study. No difference was observed either for yellowfin tuna $(50 \mathrm{~cm} F L$ threshold) or skipjack tuna ( $40 \mathrm{~cm} F L$ threshold). However, a larger sample size will be needed before conclusions can be drawn regarding the effect of fish size on the residence times of tuna associated with FADs in the Maldives. In Hawaii, Graham et al. (2007) and Robert et al. (2012) observed differences in the trophic ecology and behaviour of yellowfin tuna at FADs for size classes smaller and larger than $50 \mathrm{~cm} F L$. Future work in the Maldives should focus on similar investigations to determine whether these size effects are universal.

We found that skipjack tuna remained associated with FADs for an average of 3.5 and 0.2 days (CRTs) in January and November 2009, respectively. The same trend was observed when the data were examined at a finer scale (FCRTs). The lack of other passive acoustic tracking studies on this species at anchored FADs prevents us from making any comparison.
On drifting FADs in the Indian Ocean, Dagorn et al. (2007b) observed a mean CRT of 0.9 days. We have shown that individuals of the same size and same species (skipjack tuna) can display different CRTs at the same FAD at different times. Hence, it is very likely that the conditions around FADs directly influence the residence times of skipjack tuna. Ohta and Kakuma (2005) were unable to demonstrate any relationship between the residence times of yellowfin tuna at FADs and various oceanographic factors; therefore, we believe that biotic factors are likely to be the main drivers of residence times. Such factors may include the presence/absence of predators, local prey availability and local density of tunas around FADs. Ohta and Kakuma (2005) reported cases where a scientist observed the occurrence of a school of spinner dolphins and a false killer whale that coincided with short-term absences of monitored tunas. The presence of predators of tuna could explain some of the absences from the FADs, but monitoring such activity is not possible. The residence time of fish is also known to be influenced by local prey abundance (Pitcher and Parrish 1993). Schaefer and Fuller (2010) considered that the occurrence or absence of prey organisms within the night-time deep scattering layer (DSL) are likely to influence tuna behaviour and, thus, the length of time that they remain associated with FADs. Unfortunately, no automatic recording tool currently exists for monitoring the abundance of prey around FADs. Finally, the number of tunas around a FAD could have an effect on the residence times of individuals (Soria et al. 2009; Capello et al. 2011). Tropical tuna purse seiners use echosounder buoys to assess the amount of tuna around drifting FADs (Dagorn et al. 2012). Two of these buoys were attached to FADs 1 and 2 during the tagging experiment in January 2009. Unfortunately, both buoys were vandalised after a couple of days, preventing us from investigating a possible relationship between residency time and abundance.

In November 2009, yellowfin tuna stayed at the FADs three times longer than skipjack tuna at both scales of observation (FCRTs and CRTs). This suggests that the two species have different behaviours when associated with the same anchored FADs under the same conditions. This observed difference could be the result of two independent processes: either by the two species responding to different factors or by the species' responses being dependent on the same factor but with different thresholds.

When examining the behaviour at a fine scale, we observed that skipjack tuna stayed longer at FAD1 than at FAD2 in January 2009 (the dataset was too small to compare the FCRTs at the same FADs in November 2009). However, when the same comparison was conducted on CRTs, no differences were observed. This could be explained by different factors influencing the fine-scale and longer-term associative behaviour of skipjack tuna. In November 2009, the residence times of yellowfin tuna at the two FADs were similar at both scales. The local conditions at both FADs in November 2009 may also have been similar.

Skipjack tuna were found to leave the FADs more regularly in the afternoon (1200-1800 h) in November 2009, whilst in January no such trend was observed. For yellowfin tuna, no temporal pattern in departures was ever observed. This contradicts results from Ohta and Kakuma (2005), who 
observed distinct patterns in the time at which departures occurred for some individuals, but could not provide interpretations for these patterns. More data are required to draw definitive conclusions, but the absence of regular temporal patterns in our study suggests that the decision to leave a FAD does not depend on temporally regular processes. This supports the notion that non predictable variables control the departure of tunas from FADs. These variables may include the previously mentioned factors, such as prey, predators and conspecifics.

Tagged tunas were never observed to all leave a FAD at exactly the same time, a result which is similar to those of Dagorn et al. (2007a). Nonetheless, some pairs of tagged individuals displayed synchronous departures, i.e., within $15 \mathrm{~min}$. As no direct periodicity of departures (i.e., many fish responding to the same regular external environmental stimuli) was observed, these synchronous departures could possibly represent fish leaving the FAD in the same school. The multispecies composition of some pairs of tagged fish could even suggest the existence of mixed schools. The method used in the present study does not provide conclusive evidence that fish departing from a FAD within 15 min of one another were physically in the same school. Nevertheless, our results do highlight the need for further studies to specifically address the finescale behaviour of several fish simultaneously in the future. Studies of this nature could be conducted using alternative acoustic telemetry techniques (Espinoza et al. 2011; Capello et al. 2012), although performing such experiments around offshore anchored FADs represents a significant technological challenge.

To date, passive tracking experiments around FADs have only been conducted in Japan (Ohta and Kakuma 2005), Hawaii (Dagorn et al. 2007a; Robert et al. 2012) and the Philippines (Mitsunaga et al. 2012). These studies have primarily focused on yellowfin tuna, making it essential to extend research into the behaviour of other associative tuna species (e.g., skipjack tuna), especially when the catch ratios of the species are taken into consideration. Furthermore, considering the wide use of anchored FAD arrays throughout the world's tropical and sub-tropical regions, there is a clear need for further research of this kind to be conducted at other locations. To optimise our understanding of the behaviour of these species, we also recommend that standardised methods for comparison be adopted, to ultimately provide a worldwide perspective on the behaviour of these species at FADs. Moreover, we strongly recommend that all neighbouring FADs in the study area are equipped with acoustic receivers in order to investigate the effect of distance between FADs on the movement behaviour of tuna, as has been done in Hawaii (Dagorn et al. 2007a; Robert et al. 2012), in the present study, and on small pelagic fish (Soria et al. 2009). The use of the CRT (24 h) in all previous studies has thus far allowed comparisons to be drawn and, as such, should remain a critical variable to be reported. However, through the adoption of the FCRT, future studies could increase our understanding of this behaviour by providing more details. Finally, and most importantly, future research should include methods that allow for the simultaneous monitoring of biotic and abiotic variables around FADs; these could include the measurement of prey density, presence and abundance of conspecifics, presence and abundance of predators, oceanographic conditions and levels of fishing activity. Such information is required to better understand and explain changes seen in the associative behaviour of tuna with FADs.

Acknowledgements. The authors would like to thank the staff of the Marine Research Centre (Maldives) who took part in the field trips and maintained the array of receivers on the FADs, as well as Maldivian fishermen who aided in the capture of tunas. This work was partially financially supported by the commission of the European communities, specific RTD programme of Framework programme 7, "Theme 2 - Food, agriculture, Fisheries and biotechnology", through the research project Made (Mitigating adverse ecological impacts of open ocean fisheries), contract \#210496. This work does not necessarily reflect the commission's views and in no way represents its future policy in this area.

\section{References}

Brill R.W., Block B.A., Boggs C.H., Bigelow K.A., Freund E.V., Marcinek D.J., 1999, Horizontal movements and depth distribution of large adult yellowfin tuna (Thunnus albacares) near the Hawaiian Islands, recorded using ultrasonic telemetry: implications for the physiological ecology of pelagic fishes. Mar. Biol. 133, 395-408.

Bromhead D., Foster J., Attard R., Findlay J., Kalish J., 2003, A review of the impacts of fish aggregating devices (FADs) on tuna fisheries. Final Report to the Fisheries Resources Research Fund. Bureau of Rural Sciences, Canberra, ACT.

Capello M., Soria M., Cotel P., Deneubourg J.L., Dagorn L., 2011, Quantifying the interplay between environmental and social effects on aggregated fish dynamics. PLoS One 6(12), DOI: 10.1371/journal.pone.0028109.

Capello M., Soria M., Potin G., Cotel P., Dagorn L., 2012, Role of current and daylight variations on small-pelagic fish aggregations (Selar crumenophthalmus) around a coastal fish aggregating device (FAD) from accurate acoustic tracking. Aquat. Living Resour. 25, this volume

Castro J.J., Santiago J.A., Santana-Ortega A.T., 2002, A general theory on fish aggregation to floating objects: An alternative to the meeting point hypothesis. Rev. Fish Biol. Fish. 11, 255-277.

Cayré P., 1991, Behaviour of yellowfin tuna (Thunnus albacares) and skipjack tuna (Katsuwonus pelamis) around fish aggregating devices (FADs) in the Comoros Islands as determined by ultrasonic tagging. Aquat. Living Resour. 4, 1-12.

Cayré P., Chabanne J., 1986, Marquage acoustique et comportement de thons tropicaux (albacore ; Thunnus albacares, et listao : Katsuwonus pelamis) au voisinage d'un dispositif concentrateur de poissons. Océanogr. Trop. 21, 167-183.

Cayré P., Marsac F., 1993, Modelling the yellowfin tuna (Thunnus albacares) vertical distribution using sonic tagging results and local environmental parameters. Aquat. Living Resour. 6, 1-14.

Cox D.R., 1972, Regression models and life tables (with discussion). J. R. Stat. Soc. Ser. B 34, 187-220.

Dagorn L., Josse E., Bach P., 2000a, Individual differences in horizontal movements of yellowfin tuna (Thunnus albacares) in nearshore areas in French Polynesia, determined using ultrasonic telemetry. Aquat. Living Resour. 13, 193-202. 
Dagorn L., Bach P., Josse E., 2000b, Movement patterns of large bigeye tuna (Thunnus obesus) in the open ocean, determined using ultrasonic telemetry. Mar. Biol. 136, 361-371.

Dagorn L., Holland K.N., Itano D.G., 2007a, Behavior of yellowfin (Thunnus albacares) and bigeye (T.obesus) tuna in a network of fish aggregating devices (FADs). Mar. Biol. 151, 595-606.

Dagorn L., Pincock D., Girard C., Holland K., Taquet M., Sancho G., Itano D., Aumeeruddy R., 2007b, Satellite-linked acoustic receivers to observe behavior of fish in remote areas. Aquat. Living Resour. 20, 307-312.

Dagorn L., Holland K.N., Restrepo V., Moreno G., 2012, Is it good or bad to fish with FADs? What are the real impacts of the use of drifting FADs on pelagic marine ecosystems? Fish Fish. 13, Dizon A., Brill R., Yuen H.S., 1978, Correlations between environment, physiology and activity and the effects of thermoregulation in skipjack tuna. In: Sharp G.D., Dizon A.E. (Eds.), The Physiology Ecology of Tunas, Academic Press, New York, pp. 233-259.

Espinoza M., Farrugia T.J., Webber D.M., Smith F., Lowe C.G., 2011, Testing a new acoustic telemetry technique to quantify long-term, fine-scale movements of aquatic animals. Fish. Res. 108, 364371.

Fréon P., Dagorn L., 2000, Review of fish associate behaviour: toward a generalisation of the meeting point hypothesis. Rev. Fish Biol. Fish. 10, 183-207.

Girard C., Benhamou S., Dagorn L., 2004, FAD: fish aggregating device or fish attracting device? A new analysis of yellowfin tuna movements around floating objects. Anim. Behav. 67, 319-326

Graham B.S., Grubbs D., Holland K., Popp B.N., 2007, A rapid ontogenetic shift in the diet of juvenile yellowfin tuna from Hawaii. Mar. Biol. 150, 647-658.

Heupel M.R., Semmens J.M., Hobday A.J., 2006, Automated acoustic tracking of aquatic animals: scales, design and deployment of listening station arrays. Mar. Freshwater Res. 57, 1-13.

Holland K.N., Brill R.W., Chang R.K.C., 1990, Horizontal and vertical movements of yellowfin and bigeye tuna associated with fish aggregating devices. Fish. Bull. 88, 493-507.

Itano D.G., Holland K.N., 2000, Movement and vulnerability of bigeye (Thunnus obesus) and yellowfin tuna (Thunnus albacares) in relation to FADs and natural aggregation points. Aquat. Living Resour. 13, 213-223.

Jauhary R., 2011, Minimum residence time of skipjack (Katsuwonus pelamis) and yellowfin (Thunnus albacores) tuna in an array of anchored fish aggregation devices (AFADs) around the Maldive Islands. MSc Thesis.

Josse E., Bach P., Dagorn L., 1998, Simultaneous observation of tuna movements and their prey by sonic tracking and acoustic surveys. Hydrobiologia 371-372, 61-69.

Kleiber P., Hampton J., 1994, Modeling effects of FADs and islands on movement of skipjack tuna (Katsuwonis pelamis): estimating parameters from tagging data. Can. J. Fish. Aquat. Sci. 51, 2642 2653.

Klimley A.P., Holloway C.F., 1999, School fidelity and homing synchronicity of yellowfin tuna, Thunnus albacares. Mar. Biol. 133, 307-317.
Marsac F., Cayré P., 1998, Telemetry applied to behaviour of yellowfin tuna (Thunnus albacares) movements in a network of fish aggregating devices. Hydrobiologia 371-372, 155-171.

Meyer C.G., Holland K.N., Wetherbee B.M., Lowe C.G., 2000, Movement patterns, habitat utilization, home range size and site fidelity in the whitesaddle goatfish, Parupeneus porphyreus, in a marine reserve. Environ. Biol. Fishes 59, 235-242.

Mitsunaga Y., Endo C., Anraku K., Selorio C.M., Babaran R.P., 2012, Association of early juvenile tuna Thunnus albacores with a network of payaos in the Philippines. Fish. Sci. 78, 15-22.

Miyake M., Guillotreau P., Sun C.H., Ishimura G., 2010, Recent developments in the tuna industry: stocks, fisheries, management, processing, trade and markets. FAO Fisheries and Aquaculture Techn. Pap. No. 543, Rome.

Naeem A., Latheefa A., 1995, Biosocioeconomic assessment of the effects of fish aggregating devices in the tuna fishery in the Maldives. Bay of Bengal Programme, Madras WP/ RAS/91/006.

Ohta I., Kakuma S., 2005, Periodic behavior and residence time of yellowfin and bigeye tuna associated with fish aggregating devices around Okinawa Islands, as identified with automated listening stations. Mar. Biol. 146, 581-594.

Pincock D.G., Voegeli F.A., 1990, Quick course in underwater telemetry system. Vemco Limited.

Pitcher T.J., Parrish J.K., 1993, Functions of shoaling behavior in teleost. In: Behaviour of teleost fishes, 2nd edn. Chapman and Hall, London, pp. 363-439.

Robert M., Dagorn L., Deneubourg J.L., Itano D., Holland K., 2012, Size-dependent behaviour of tuna in an array of fish aggregating devices (FADs). Mar. Biol. 159, 907-914.

Schaefer K.M., Fuller D.W., 2002, Movements, behavior, and habitat selection of bigeye tuna (Thunnus obesus) in the eastern equatorial Pacific, ascertained through archival tags. Fish Bull. 100, 765-788.

Schaefer K.M., Fuller D.W., 2005, Behavior of bigeye (Thunnus obesus) and skipjack (Katsuwonus pelamis) tunas within aggregations associated with floating objects in the equatorial eastern Pacific. Mar. Biol. 146, 781-792.

Schaefer K.M., Fuller D.W., 2010, Vertical movements, behaviour and habitat of bigeye tuna (Thunnus obesus) in the equatorial eastern Pacific Ocean, ascertained from archival tag data. Mar. Biol. 157, 2625-2642.

Shainee M., Leira B.J., 2011, On the cause of premature FAD loss in the Maldives. Fish Res. 109, 42-53.

Shiham M.A., 2004, Country review - Maldives. Review of the state of world marine capture fisheries management: Indian Ocean.

Soria M., Dagorn L., Potin G., Fréon P., 2009, First field-based experiment supporting the meeting point hypothesis in pelagic fish. Anim. Behav. 78, 1441-1446.

Stéquert B., Ramcharrun B., 1996, La reproduction du listao (Katsuwonus pelamis) dans le bassin ouest de l'océan Indien. Aquat. Living Resour. 9, 235-247.

Yuen H.S.H., 1970, Behavior of skipjack tuna, Katsuwonis pelamis, as determined by tracking with ultrasonic devices. J. Fish. Res. Board Can. 27, 2071-2079. 